\section{Reactivation of hepatitis B virus infection in patients with hematologic disorders}

\author{
Bo Wang, ${ }^{1}$ Ghulam Mufti ${ }^{2}$ and Kosh Agarwal ${ }^{1}$ \\ ${ }^{1}$ Institute of Liver Studies and ${ }^{2}$ Department of Hematology, King's College Hospital, \\ London, UK
}

\section{ABSTRACT}

$\mathrm{H}$ epatitis $B$ reactivation is the reappearance or rise of hepatitis $B$ virus (HBV) DNA in patients with past or chronic HBV infection, usually occurring in the context of immunosuppression. HBV reactivation has been most commonly reported in patients with hematologic disorders, with potentially serious and life-threatening consequences. In this review, we discuss the basis and presentation of $\mathrm{HBV}$ reactivation, and risk factors in terms of the host, the virus and the immunosuppression regimen, including newer agents used to manage hematologic malignancies. We overview the management of HBV reactivation, highlighting an up-dated recommendation on the use of newer nucleoside and nucleotide analogs, such as tenofovir and entecavir, for antiviral prophylaxis.

\section{Introduction}

Hepatitis B reactivation is the reappearance or rise of hepatitis B virus (HBV) DNA in the serum of patients with past or chronic HBV infection. Reactivation can occur in a variety of clinical settings, usually in the context of an immunosuppressed state or immunosuppressive therapy. HBV reactivation has been most commonly reported in patients receiving chemotherapy for hematologic malignancies and following hematopoietic stem cell transplants. ${ }^{1}$ An estimated 2 billion people worldwide have serological evidence of either past or present $\mathrm{HBV}$ infection, with around 240 million people chronically infected. ${ }^{2}$ The prevalence varies globally, ranging between $2 \%$ in Europe to over 10\% in East Asia; in the UK it is estimated to be between 0.5-1.7\%, with areas of greater ethnic diversity such as London having a higher prevalence of approximately $2.4 \%{ }^{2,3}$ Therefore, there is a clear potential for HBV reactivation to cause significant morbidity, and even mortality, if not appropriately diagnosed and managed.

Management of HBV in general is undergoing a paradigm shift. Recently up-dated clinical practice guidelines from the European Association for the Study of the Liver (EASL) have redefined the natural history of chronic HBV, driven by a better understanding of the interactions between the virus and the host immune system. ${ }^{4}$ From a therapeutic point of view, existing agents effectively suppress virus replication and lower serum HBV DNA concentrations, but the goal now is to develop novel agents that can offer functional cure of HBV., 5,6 This is defined as the loss of hepatitis B surface antigen (HBsAg), the hallmark of chronic infection. Complete sterilizing cure is not considered possible due to the persistence of HBV DNA within hepatocytes. However, if functional cure becomes a realistic treatment end point, the number of patients with resolved HBV infection but who remain at risk of reactivation may increase significantly.

Previous guidelines have been heterogeneous in their recommendations for the assessment of HBV reactivation, especially with regards to patient selection for testing and choice of antiviral prophylaxis. In this review, we aim to provide a practical overview of HBV reactivation at a time when the management of $\mathrm{HBV}$ is changing and the therapeutic options are expanding for patients with hematologic disorders, who are at the highest risk of this potentially life-threatening complication.

\section{Hepatitis B virus reactivation and clinical presentation}

Chronic HBV infection is defined by the presence of HBsAg in serum with vari-
Haematologica 2019

Volume 104(3):435-443

\section{Correspondence:}

BO WANG

bo.wang@nhs.net

Received: November 22, 2018.

Accepted: January 18, 2019.

Pre-published: February 7, 2019.

doi:10.3324/haematol.2018.210252

Check the online version for the most updated information on this article, online supplements, and information on authorship \& disclosures: www.haematologica.org/content/104/3/435

\section{(C)2019 Ferrata Storti Foundation}

Material published in Haematologica is covered by copyright. All rights are reserved to the Ferrata Storti Foundation. Use of published material is allowed under the following terms and conditions:

https://creativecommons.org/licenses/by-nc/4.0/legalcode. Copies of published material are allowed for personal or internal use. Sharing published material for non-commercial purposes is subject to the following conditions: https://creativecommons.org/licenses/by-nc/4.0/legalcode, sect. 3. Reproducing and sharing published material for commercial purposes is not allowed without permission in writing from the publisher. 
able HBV DNA levels depending on the balance between HBV replication and immune control.' Up-dated nomenclature regarding the phases of $\mathrm{HBV}$ infection reflect this and broadly classify patients into hepatitis $\mathrm{B}$ e antigen ( $\mathrm{HBe} \mathrm{Ag})$ positive or negative, and whether or not there is evidence of a chronic hepatitis (Table 1). ${ }^{4}$ Those with resolved HBV infection are HBsAg negative and have circulating anti-core antibody (anti-HBc), and often anti-surface antibody (anti-HBs). Although such patients are considered to have past HBV infection, HBV DNA persists within the liver in the form of highly stable covalently closed circular DNA (cccDNA) and integrated DNA. ${ }^{8}$ Active replication is controlled by both innate and adaptive immune responses, including HBV-specific T-cell responses and neutralizing antibodies produced by activated $B$ cells. However, these responses are not sufficient to eradicate all latent forms of HBV DNA and a reservoir of persistent HBV exists. With immunosuppression due to any cause, immune-mediated control of $\mathrm{HBV}$ replication is lost and reactivation can occur. 9

Hepatitis $B$ virus reactivation includes both exacerbation of chronic hepatitis B infection in an $\mathrm{HBs} A g$-positive patient (with $\geq 2 \log _{10}$ rise in HBV DNA level) and true reactivation of resolved hepatitis $B$ infection, which can either be reverse $\mathrm{HBsAg}$ seroconversion (reappearance of $\mathrm{HBsAg}$ ) or detection of HBV DNA with negative HBsAg. These virological events are often followed by a reactivation-related hepatitis (increase in ALT or AST $\geq 3 \times$ baseline). In severe cases, or where reactivation is not recognized and there is a delay in treatment, hepatitis may progress to jaundice and potentially fulminant hepatic failure. More commonly, however, HBV DNA falls again either due to immune control or antiviral therapy, and the patient recovers..$^{10}$

Studies of HBV reactivation during chemotherapy for lymphoma have demonstrated that viral reactivation itself can occur at any time during or after immunosuppression, but the hepatitis and clinical manifestations related to reactivation typically occur after treatment has ended when immune reconstitution takes place. ${ }^{11}$ In B-cell depletive therapies, such as rituximab, risk of reactivation is protracted, with cases reported up to two years after the last dose. ${ }^{12}$ Furthermore, HBV reactivation after hematopoietic stem cell transplantation (HSCT) may occur several years after transplantation because of the potential long delay in immune reconstitution..$^{13}$ Therefore, reactivation may be ongoing over an extended period of time before therapy can be implemented, and requires long-term follow up and surveillance.

\section{Risk factors}

Factors pertaining to the host, the virus, the immunosuppressive regimen, and the underlying disease itself can all impact on the risk of HBV reactivation. Male sex and older age ( $\geq 50$ years) have been associated with increased risk. One study of more than $600 \mathrm{HBsAg}$-positive patients receiving chemotherapy for a range of cancers showed an almost 3-fold increased incidence in men, although the reason for this was not clear. ${ }^{14}$ Older patients are more likely to have HBsAg seroclearance but persistent levels of total HBV DNA and cccDNA in the liver, hence increasing the risk of reactivation. ${ }^{15}$ Viral factors associated with reactivation have been shown to include HBsAg positivity, HBeAg positivity, and elevated HBV DNA levels prior to commencing immunosuppressive therapy, all of which reflect a state of poor HBV-specific immune control prior to immunosuppression. ${ }^{16,17}$ Conversely, possessing antiHBs antibodies has been suggested to be protective against reactivation, although it has not been determined whether the specific titer has any effect. ${ }^{18}$ More recently, co-infection of $\mathrm{HBV}$ with other viruses such as HIV and hepatitis $\mathrm{C}$ virus (HCV) has been highlighted as a risk factor for reactivation even without the influence of immunosuppression. Treatment of HBV/HCV co-infected individuals with direct acting antivirals against $\mathrm{HCV}$ can result in HBV reactivation, although the clinical significance of this may be minimal. ${ }^{19,20}$ The mechanism of this observation is thought to be either a direct inhibitory effect of HCV replication on HBV or that immune responses against HCV also suppress HBV replication. ${ }^{21}$

The risk of HBV reactivation may be determined in part by the underlying disease, although studies comparing similar treatments in different hematologic diseases are lacking. Lymphoma has been the most common underlying condition in reports of reactivation; whether this is a reflection of the disease itself or the treatments given is not clear. An association between chronic HBV infection and non-Hodgkin lymphoma (NHL) has long been postulated and several studies have accumulated evidence to support this; a meta-analysis of more than 3000 patients with NHL and over 1 million controls showed an overall odds ratio of 2.56 for detecting HBsAg positivity in patients with NHL. ${ }^{22}$ A higher prevalence of anti-HBc positivity alone in NHL patients has also been demonstrated. Possible mechanisms to explain the association include direct HBV infection of lymphocytes, and chronic antigenic stimulation and associated B-cell proliferation. ${ }^{23,24}$

Table 1. Up-dated nomenclature for natural history phases of chronic hepatitis B virus (HBV) infection, adapted from the 2017 EASL Clinical Practice Guidelines.

\begin{tabular}{lcccc} 
& Chronic infection & HBeAg positive & \multicolumn{2}{c}{ HBeAg negative } \\
Chronic hepatitis & Chronic infection & Negative \\
HBeAg & Positive & Positive & Negative & $>2000 \mathrm{IU} / \mathrm{mL}$ \\
HBV DNA & $>10^{7} \mathrm{IU} / \mathrm{mL}$ & $10^{4}-10^{7} \mathrm{IU} / \mathrm{mL}$ & $<2000 \mathrm{IU} / \mathrm{mL}^{*}$ & Elevated** \\
ALT & Normal & Elevated & Normal & Moderate/severe \\
Liver disease & None/minimal & Moderate/severe & None & HBeAg negative chronic hepatitis
\end{tabular}

EASL: European Association for the Study of the Liver; HBeAg: hepatitis B e antigen; ALT: alanine transaminase. *Can be 2000-20000 IU/mL in some patients without signs of chronic hepatitis. **Either persistently or intermittently. 
Finally, the immunosuppression regimen itself is of great importance in the risk of reactivation, and numerous studies have attempted to stratify this risk. ${ }^{25}$ High risk is considered to be greater than $10 \%$, moderate between 1 $10 \%$, and low risk less than $1 \%$; the degree of risk has implications on management (Table 2). Low-risk regimens are limited to traditional immunosuppressive agents such as azathioprine and oral low-dose methotrexate without combination steroids, short-term low-dose steroids $(\leq 20$ $\mathrm{mg}$ /day prednisolone or equivalent for $\leq 7$ days), and intraarticular steroids. The specific treatments relevant to hematologic disorders will be discussed in more detail below.

\section{Specific immunosuppressive treatments}

\section{Systemic cancer chemotherapy}

The earliest studies of HBV reactivation were in the context of systemic chemotherapy for breast cancer and lymphoma. The greatest rates of reactivation were found in patients with lymphoma, likely due to the potency of immunosuppression offered by the chemotherapy regimens, as well as the immunosuppressive effect of the underlying disease. In one prospective study of patients treated for lymphoma with a variety of chemotherapy regimens, mostly based on $\mathrm{CHOP}$ (cyclophosphamide, doxorubicin, vincristine, prednisolone), the rate of hepatitis attributed to HBV reactivation was $48 \%$ in $\mathrm{HBs} A g-$ positive patients (13 out of 27 ) and $4 \%$ in patients positive for anti-HBc and/or anti-HBs ( 2 out of 51 patients). ${ }^{11}$ A similar study of patients receiving chemotherapy for other solid tumors found HBV reactivation in 15 out of $78 \mathrm{HBsAg-}$ positive patients. ${ }^{14}$ In a large meta-analysis, the risk of HBV reactivation was found to be highest with anthracycline-derived chemotherapy such as doxorubicin and epirubicin. ${ }^{26}$

\section{Corticosteroids}

The negative effect of corticosteroids on HBV infection has long been documented, with early studies from the 1980s that aimed to investigate a therapeutic role for prednisolone instead showing a hastened biochemical deterioration and increased complications, including death. $^{27}$ The mechanism is potentially 2 -fold: firstly, the HBV genome contains a glucocorticoid-responsive transcription regulatory element which is up-regulated by corticosteroids resulting in increased viral replication, and secondly, a directly suppressive effect on cytotoxic T cells which are involved in HBV control. ${ }^{28}$ Reactivation has been reported with steroid monotherapy, with one metaanalysis concluding the risk to be at least 10\% in HBsAgpositive patients receiving continuous systemic treatment for four weeks or more. ${ }^{25}$ It also concluded that doses of $\geq 20 \mathrm{mg}$ daily of prednisolone or equivalent represented a high risk. In patients with hemato-oncological disorders, corticosteroids are often used in conjunction with other chemotherapy agents, where they have been shown to have an additive deleterious effect. In one randomized study, $50 \mathrm{HBsAg}$ positive patients received the same chemotherapy regimens for NHL either with or without corticosteroids; the incidence of reactivation in the corticosteroid group was significantly higher (18 out of 25 vs. 9 out of 25, respectively), with also a higher incidence of clinically significant hepatitis. ${ }^{29}$

\section{Anti-CD20-directed monoclonal antibodies}

This class of drugs is well-reported for causing severe HBV reactivation, with several published cases of fatal fulminant hepatic failure. ${ }^{30-34}$ These reports and a formal evaluation of the post-marketing data from the US Food and Drug Administration (FDA) adverse events reporting system resulted in a warning on the packaging of all monoclonal antibodies against CD20 regarding the risk of HBV reactivation. Rituximab, ofatumumab and obinutuzumab are currently licensed and predominantly used to treat Bcell malignancies. The risk of reactivation is highest for HBsAg-positive patients, and it has even been suggested that almost all will develop reactivation at some point. ${ }^{25}$ Patients with resolved HBV infection are also likely to be at high risk. In one large analysis of 326 anti-HBc positive patients receiving rituximab or obinutuzumab as part of

Table 2. Risk groups in terms of immunosuppressive regimen and the recommended management to prevent hepatitis B virus (HBV) reactivation.

\begin{tabular}{|c|c|c|c|}
\hline \multirow{2}{*}{ Risk group } & \multirow[t]{2}{*}{ Treatment regimen } & \multicolumn{2}{|c|}{ Recommended management } \\
\hline & & HBsAg positive & $\begin{array}{l}\text { HBsAg negative, } \\
\text { anti-HBc positive }\end{array}$ \\
\hline High risk (>10\%) & $\begin{array}{l}\text { B-cell-depleting anti-CD20-directed } \\
\text { monoclonal antibodies (e.g. rituximab) } \\
\text { HSCT +/- diagnosis of GvHD }\end{array}$ & $\begin{array}{l}\text { Treatment/prophylaxis* } \\
\text { with TDF/entecavir }\end{array}$ & $\begin{array}{c}\text { Prophylaxis with lamivudine, } \\
\text { or TDF/entecavir if expected } \\
\text { duration }>12 \text { months }\end{array}$ \\
\hline
\end{tabular}

Systemic cancer chemotherapy - anthracycline derivatives (e.g. doxorubicin)

\begin{tabular}{|c|c|c|c|}
\hline Moderate risk (1-10\%) & $\begin{array}{l}\text { Tyrosine kinase inhibitors } \\
\text { (e.g. imatinib, ibrutinib) } \\
\text { Corticosteroids } \geq 20 \mathrm{mg} \\
\text { prednisolone, } \geq 4 \text { weeks }\end{array}$ & $\begin{array}{l}\text { Treatment/prophylaxis* } \\
\text { with TDF/entecavir }\end{array}$ & $\begin{array}{c}\text { Prophylaxis with lamivudine, or } \\
\text { TDF/entecavir if expected } \\
\text { duration }>12 \text { months }\end{array}$ \\
\hline Low risk $(<1 \%)$ & $\begin{array}{l}\text { Traditional immunosuppressive } \\
\text { monotherapy (e.g. azathioprine, } \\
\text { methotrexate) }\end{array}$ & $\begin{array}{l}\text { Treatment/prophylaxis* with } \\
\text { TDF/entecavir if chronic hepatitis }\end{array}$ & $\begin{array}{l}\text { Monitor HBsAg, ALT and HBV } \\
\text { DNA every } 3 \text { months }\end{array}$ \\
\hline
\end{tabular}

Corticosteroids $\leq 4$ weeks

*HBsAg-positive patients with evidence of chronic HBV hepatitis (see Table 1) will require active treatment of HBV infection. HSCT: hematopoietic stem cell transplantation; GvHD: graft-versus-host disease; TDF: tenofovir disoproxil fumarate; HbsAg: hepatitis B surface antigen; anti-HBc: anti-hepatitis B core antibody; ALT: alanine transaminase. 
chemotherapy for NHL, 27 patients $(8.2 \%)$ in total had HBV reactivation; of these, 17 had received obinutuzumab and 10 rituximab. ${ }^{35}$ The mechanism of action of these drugs in causing depletion of circulating B cells and partial depletion in the lymphatic system and bone marrow explains the strong association with HBV reactivation: a fall in anti-HBs antibody titers has been demonstrated in patients undergoing rituximab therapy, with reactivation seen most in those with complete loss of anti-HBs. ${ }^{36} \mathrm{~A}$ large meta-analysis of over 800 patients with resolved HBV infection receiving rituximab also demonstrated a protective effect of possessing anti-HBs, with $14 \%$ of those who were only anti-HBc positive developing reactivation compared with $5 \%$ of those also positive for antiHBs. ${ }^{18}$ The risk of reactivation associated with this class of drugs also potentially persists for longer than with other therapies. Reactivation events have been reported up to two years after the last dose of rituximab; one prospective study of 63 anti-HBc positive patients with lymphoma reported a cumulative rate of $\mathrm{HBV}$ reactivation of $41.5 \%$ over two years, with a median time to reactivation of 23 weeks, but a range of up to 100 weeks. ${ }^{12}$ Again, in this study, possession of anti-HBs antibodies was protective against reactivation, with the 2-year cumulative rate of reactivation being significantly higher in those negative for anti-HBs. The wide range and potential delay in presentation of reactivation mirrors the scenario of a hepatic flare after rituximab treatment of HCV-related lymphomas, and possibly relates to variation in the strength of immune control of HBV in different individuals. ${ }^{37}$

Monoclonal antibodies directed against other immune cell targets have also been associated with reactivation. Alemtuzumab, a monoclonal antibody against CD52 used for refractory chronic lymphocytic leukemia (CLL) and in HSCT conditioning regimens, has been reported to cause reverse $\mathrm{HBsAg}$ seroconversion and significant reactivation-related hepatitis. ${ }^{38,39}$ Furthermore, as newer agents are developed, emerging cases of HBV reactivation are also being reported, including fatalities: mogamulizumab, a treatment for T-cell lymphoma, and brentuximab vedotin, used in the treatment of refractory or relapsed Hodgkin lymphoma, are two recent examples. ${ }^{40-42}$ Daratumumab, a monoclonal antibody against CD38 which is overexpressed in B-cell hematologic malignancies, also has the potential for reactivation given its mechanism of action, but so far no reports have emerged.

\section{Hematopoietic stem cell transplantation}

Hepatitis B virus reactivation in the context of allogeneic HSCT is well-recognized and represents a high risk, ranging from $40 \%$ over two years in patients with resolved infection to $70-86 \%$ over five years in $\mathrm{HBs} A g$-positive recipients. ${ }^{4,44}$ Risk factors are similar to those for reactivation in general, including older age ( $\geq 50$ years) and detectable HBV DNA prior to transplant. ${ }^{45,46}$ Development of graft-versus-host disease (GvHD) also significantly increases the risk of HBV reactivation, with one study of 85 anti-HBc positive recipients of allogeneic HSCT showing a cumulative rate at two years of $79.5 \%$ compared with $21 \%{ }^{44}$ This increased risk is likely associated with the fact that patients with GvHD receive more immunosuppression therapy, and experience a delay in reconstitution of the immune system for up to 12-18 months. ${ }^{47} \mathrm{HBV}$ reactivation after autologous HSCT is also recognized, although data are more limited. In one study of $32 \mathrm{HBs} \mathrm{Ag}$ - positive patients with NHL undergoing high-dose chemotherapy and autologous HSCT, the incidence of hepatitis due to HBV reactivation was 50\% ${ }^{48}$ In anti-HBc positive patients, the risk is predictably lower; one study found reactivation in 7 out of $107(6.5 \%)$ patients. ${ }^{49}$

In considering HBV reactivation post HSCT, the HBV status of the donor has been shown to have significant impact. It is known that, in allogeneic HSCT, donor vaccination can result in transfer of immunity against a range of infectious antigens, including hepatitis $\mathrm{B}^{50,51}$ More recently, it has been demonstrated that recipients of HSCT who have chronic or resolved HBV infection can also benefit from donors who have been vaccinated against HBV with a strong anti-HBs response. In one series, $3 \mathrm{HBsAg-posi-}$ tive patients received allogeneic HSCT from vaccinated donors with a high anti-HBs titer. All 3 recipients became HBsAg-negative post transplant and developed a strong humoral HBV-specific response with high titers of antiHBs antibody as well as detectable T-cell immunity. ${ }^{43}$ In 2 of the recipients, the underlying hematologic malignancy subsequently relapsed, and in each case, anti-HBs levels declined and the patients again became $\mathrm{HBsAg}$ positive with detectable HBV DNA. This demonstrates a unique situation where the risk of HBV reactivation may be modified not only by management of the recipient, but also by careful donor selection.

\section{Other novel agents}

With the rapid expansion of treatment options for conditions such as multiple myeloma and CLL, there are novel therapies that are worthy of attention as potential causes of HBV reactivation, although evidence is limited to individual reports. Tyrosine kinase inhibitors such as imatinib and nilotinib are thought to be associated with a moderate risk of HBV reactivation. ${ }^{52.55}$ As tyrosine kinase receptor-mediated signaling pathways are involved in immune activation and proliferation of lymphocytes, it is not unexpected that therapeutic blockade of these pathways may suppress immune control of HBV and result in reactivation. The newer agents ibrutinib (a Bruton tyrosine kinase inhibitor) and idelalisib (a PI3K tyrosine kinase inhibitor) are both B-cell receptor signaling modulators used for the treatment of CLL and certain NHLs. Both have been associated with cases of HBV reactivation; a recent recommendation has been issued by manufacturers of ibrutinib acknowledging the risk of HBV reactivation and advising serological testing for HBV prior to starting treatment. ${ }^{56}$

Bortezomib, a proteasome inhibitor that has revolutionized the medical management of multiple myeloma, and ruxolitinib, an inhibitor of Janus-activated kinases (JAK) used for treatment of myelofibrosis have both been associated with reported cases of HBV reactivation. ${ }^{57-59}$ Bortezomib therapy is often given prior to autologous HSCT, and along with the immune dysfunction associated with multiple myeloma itself, it is difficult to isolate the specific risk attributable to bortezomib alone. Nonetheless, reactivation has been reported both in HBsAg-positive and anti-HBc positive patients. ${ }^{57}$

Immune checkpoint inhibitors as a group of drugs are increasingly used in the treatment of various non-hematologic cancers such as melanoma, renal cell carcinoma and hepatocellular carcinoma. ${ }^{60}$ Their role in treating hematologic malignancies such as Hodgkin lymphoma is also evolving. Their mechanism of action in overcoming T-cell 


\section{Key Points}

- All patients undergoing immunosuppressive drug therapy and interventions such as HSCT should be screened for HBV infection prior to initiation of therapy, including testing for HBsAg, HBV DNA, anti-HBC antibody and anti-HBs antibody.

- Patients with serological evidence of past or active HBV infection should be assessed by an appropriate specialist hepatitis service.

- All HBsAg-positive patients should be considered high-risk for reactivation and require antiviral treatment prior to immunosuppressive therapy with a third-generation nucleoside/nucleotide analog.

- Anti-HBc positive patients receiving an immunosuppressive drug regimen considered to be high-risk for causing reactivation (e.g. antiCD20 monoclonal antibodies) should be offered prophylactic antiviral treatment.

- The risk of HBV reactivation may be protracted and monitoring and/or antiviral treatment may be required for up to 1 year after the immunosuppressive treatment has been completed.

dysfunction results in an association with immune-related side effects; hepatotoxicity is not uncommon and usually relates to an autoimmune-type hepatitis. ${ }^{61}$ Hepatitis related to exacerbation of $\mathrm{HBV}$ infection has also been reported in patients who were subsequently found to be $\mathrm{HBsAg}$ positive. ${ }^{62,63}$ The risk of reactivation in those who are only anti- $\mathrm{HBc}$ positive is thought to be low. ${ }^{9}$ Interestingly, checkpoint inhibitors are also being investigated in the treatment of chronic hepatitis B by potentially overcoming the T-cell exhaustion that is observed. ${ }^{64}$

Venetoclax, a small molecule inhibitor of BCL-2 which is over-expressed in malignant $B$ cells, is used in refractory cases of CLL. No specific cases of HBV reactivation have been reported, but as venetoclax decreases total white cell counts and can cause lymphopenia in addition to neutropenia, it may be capable of inducing reactivation. Similarly, azacitidine and decitabine are hypomethylating agents which have been increasingly used to treat acute myeloid leukemia (AML), especially in the elderly. Their potential to cause myelosuppression raises the potential risk of reactivation, but as yet no reports have emerged. With all these novel agents, reports or series of their use and safety in patients with chronic or resolved hepatitis B are warranted.

\section{Management of hepatitis B virus reactivation}

\section{Screening}

Ideal management and prevention of $\mathrm{HBV}$ reactivation includes both stringent identification of at risk patients prior to initiation of any immunosuppressive therapy, and appropriate consideration of prophylactic antiviral treat- ment. As the majority of people with chronic or past HBV are not aware of their infection, it has been strongly recommended by several international societies and guidelines that all patients should be screened for HBV prior to commencing any immunosuppressive therapy. $4,9,25,65$ Given the significant risk of reactivation associated with resolved HBV infection and certain regimens, this should include testing for both $\mathrm{HBsAg}$ and anti- $\mathrm{HBc}$ antibody. Testing for anti-HBs antibodies may also be beneficial, as those without anti-HBs are considered to be at even higher risk. However, at the moment, no recommendations have been made concerning stratifying management according to anti-HBs presence or titer.

If during screening a new $\mathrm{HBsAg-positive} \mathrm{patient} \mathrm{is}$ identified, he or she should be referred to an appropriate specialist hepatitis service to undergo full assessment, regardless of the plans for immunosuppression. Assessment will focus on defining the phase of $\mathrm{HBV}$ infection (Table 1), differentiating between chronic HBV infection and chronic hepatitis, and staging the liver disease with a combination of imaging, liver biopsy, and/or noninvasive methods such as transient elastography (FibroScan). Patients positive for anti-HBc antibody may also require assessment, as they may still present with advanced liver disease, even in the absence of active HBV viremia. In rare cases, anti- $\mathrm{HBc}$ positivity may also represent true occult HBV infection, where the patient is HBsAg-negative but has positive serum HBV DNA. This can be due to virus mutations in surface antigen rendering it undetectable with standard $\mathrm{HBsAg}$ assays or, more commonly, strongly suppressed but active viral replication. ${ }^{6}$ Such patients are managed the same as those who are HBsAg-positive. 


\section{Treatment}

Treatment of HBV reactivation can either be prophylactic or pre-emptive; the former approach offers antiviral treatment to all patients considered at moderate or high risk prior to commencing immunosuppression, whereas the latter involves regular monitoring of ALT, $\mathrm{HBs} A g$, and HBV DNA during treatment, with antiviral therapy started when HBV DNA and/or ALT levels rise. ${ }^{9}$ Studies have compared the two strategies and found prophylactic treatment to be more effective in preventing reactivation. ${ }^{67-69}$ One study comparing prophylactic versus pre-emptive antiviral therapy in HBsAg-positive patients undergoing chemotherapy for NHL found significantly lower rates of reactivation and hepatitis in the prophylactic group $(11.5 \%$ vs. $56 \% ; P=0.001) .{ }^{69}$ Similarly, a study of 80 anti$\mathrm{HBc}$ positive patients treated with rituximab for lymphoma also demonstrated that prophylactic antiviral therapy resulted in lower rates of reactivation (4.3\% vs. $23.9 \%$ at 18 months after chemotherapy; $P=0.019) .{ }^{68}$ In considering who requires prophylactic antiviral treatment, one needs to assess the risk of reactivation, as discussed earlier, both in terms of the individual patient and the immunosuppressive therapy being considered (Table 2).

\section{HBsAg-positive patients}

Following referral to a specialist service, these patients should receive nucleoside / nucleotide analog antiviral therapy prior to commencement of immunosuppression. ${ }^{4}$ This will either be active treatment in those with chronic HBV hepatitis who would require antiviral therapy in any event, or prophylaxis in those with chronic infection without hepatitis. HBV DNA and ALT should be monitored every three months throughout immunosuppression. For patients with chronic HBV infection without hepatitis, if the underlying infection remains stable following completion of immunosuppression then it may be appropriate to stop prophylactic antiviral therapy (see below: Duration of therapy). HBsAg-positive patients may also require surveillance for hepatocellular carcinoma, which would be undertaken as part of a specialist review.

\section{Anti-HBC positive patients}

The risk of reactivation in this group of patients varies and management depends mostly on the immunosuppression regimen proposed. Antiviral prophylaxis is strongly recommended in all patients receiving high-risk $(>10 \%)$ regimens such as rituximab or HSCT. Those receiving low-risk $(<1 \%)$ regimens, such as short course low-dose corticosteroids, do not require prophylaxis and can be monitored with regular ALT, HBsAg, and HBV DNA testing. There is some debate regarding those in the intermediate category of moderate risk (1-10\%), with some recommending prophylaxis ${ }^{25}$ and others recommending monitoring and a pre-emptive approach. ${ }^{4}$ Patients in this group may require an individualized evaluation and consideration of other factors, such as co-morbidities and the likely duration of immunosuppression required.

For HBsAg-positive patients requiring active or prophylactic antiviral treatment, third-generation nucleoside / nucleotide analogs such as tenofovir disoproxil fumarate (TDF) and entecavir are generally recommended. ${ }^{4}$ Until recently, the recommendation for anti-HBc positive patients has been to use lamivudine for prophylaxis. Large meta-analyses have demonstrated the efficacy of lamivudine in significantly reducing the rate of reactivation and related mortality in the setting of systemic chemotherapy ${ }^{70,71}$ However, lamivudine is associated with drug-resistant HBV mutants due to its relatively inferior antiviral potency, and rates of lamivudine resistance have been shown to be as high as $56 \%$ after two years of treatment. ${ }^{72}$ Given that some of the immunosuppressive treatments discussed above may continue for more than one year or be given in repeated courses, prolonged antiviral prophylaxis and resistance may be a significant issue. Therefore, there has been a shift in recommendation towards use of TDF or entecavir for prophylaxis in anti-HBc positive patients if immunosuppression is likely to be prolonged or with very high-risk regimens. The efficacy of entecavir in prophylaxis against HBV reactivation has been demonstrated in large comparator studies with lamivudine, whereas the data for TDF are more limited. ${ }^{73,74}$ One study of HBsAg-positive patients receiving rituximab-based therapy for diffuse large B-cell lymphoma showed significantly lower rates of HBV reactivation in those treated with entecavir $(6.6 \%$ vs. $30 \%)$, as well as lower rates of chemotherapy disruption. Therefore, current recommendations suggest lamivudine should only be considered for anti-HBc positive patients requiring short duration $(<12$ months) prophylaxis in the setting of moderate- or lowrisk immunosuppression.

\section{Safety}

Extensive data regarding long-term TDF and entecavir use in terms of efficacy and safety have been reported in the setting of management of chronic HBV infection. The main concerns surrounding long-term TDF use are renal toxicity with reduction in glomerular filtration rate, and bone toxicity with a decline in bone mineral density. ${ }^{75}$ These are potentially of additional concern in patients with hematologic disorders, and long-term safety data specifically in such patients are lacking. As for any patient on TDF, close monitoring of renal function with measurement of estimated glomerular filtration rate and serum phosphate is recommended. Recently, tenofovir alafenamide (TAF), a prodrug that results in lower circulating plasma levels of tenofovir, has been licensed for use in chronic HBV infection in patients with TDF-related toxicity and/or renal co-morbidities. Results at 96 weeks of a randomized, double blind study have demonstrated noninferiority compared with TDF in terms of antiviral potency with an improved safety profile..$^{7-78}$ In patients with existing renal/bone disease, or in whom the potential toxicity associated with TDF is unacceptable, entecavir or TAF are good alternatives. ${ }^{4}$

\section{Duration of therapy}

For patients with chronic HBV-related hepatitis, antiviral therapy with nucleoside / nucleotide analogs is long-term. In patients for whom antiviral therapy was started for prophylaxis alone, the evidence to support recommendations on the total duration required is not robust and such recommendations are based on cases of when reactivation has occurred. ${ }^{25}$ Antiviral prophylaxis for a minimum of six months after completion of chemotherapy or immunosuppression is recommended; in the case of rituximab and Bcell depleting therapies, as reactivation has been reported later, the recommendation is for prophylaxis to continue for a minimum of 12 months. The situation following HSCT is more complex and depends on occurrence of complications such as GvHD, and the viral status of the recipient and 
donor. Decisions to stop prophylaxis will likely need to be made on an individual basis, aided by regular monitoring of viral markers, including anti-HBs antibody titers. For all patients, monitoring including ALT, HBsAg and HBV DNA should continue for at least six months after prophylaxis has been stopped, as cases of reactivation after stopping antiviral treatment have been reported..$^{79}$

\section{Hepatitis B virus vaccination}

Given the importance of anti-HBs in potentially reducing the risk of HBV reactivation, the role of HBV vaccination has been investigated, specifically in the setting of HSCT ${ }^{80,81}$ In one study of 46 patients with past HBV infection undergoing HSCT, 21 patients received a standard 3dose regimen of HBV vaccine post transplant. None of these patients developed HBV reverse seroconversion compared with 12 out of 25 patients in the non-vaccine group $(P=0.0003$ ), even after a median follow up of 67 months. Further studies are required, but vaccination, in its simplicity, presents an attractive strategy to manage reactivation.

\section{Conclusion}

Hepatitis B virus reactivation is not uncommon in patients with hematologic disorders and malignancies, and ongoing reports of significant morbidity, or even fatalities, make this an important topic to understand and manage appropriately. Given the efficacy of antiviral prophylaxis, the key to preventing reactivation is identifying patients at risk. All patients need to be screened for $\mathrm{HBV}$, including $\mathrm{HBsAg}$ and anti-HBc antibody, before any immunosuppressive therapy is initiated. Furthermore, it is important to assess and understand the risk posed by individual treatment regimens in order to determine the need for antiviral prophylaxis and the duration of treatment. For those patients identified as requiring antiviral treatment or prophylaxis, a shift towards newer nucleoside / nucleotide analogs tenofovir and entecavir is recommended, especially in high-risk and prolonged regimens. Areas worthy of future research include identifying more sensitive ways of stratifying risk, especially for the large number of patients with resolved HBV infection; these may be serological viral markers that better reflect the burden of latent forms of HBV DNA in the liver and their transcriptional activity, or, indeed, immune markers that indicate the strength or type of immune control and whether they are likely to be affected by immunosuppression. Better risk stratification may allow us to be more selective about who requires prophylaxis, but until then, a low threshold approach is required to prevent the significant morbidity and mortality associated with reactivation.

\section{References}

1. Keam B, Lee JH, Im SA, et al. Why, when, and how to prevent hepatitis $B$ virus reactivation in cancer patients undergoing chemotherapy. J Natl Comp Canc Netw. 2011;9(5):465-477

2. Schweitzer A, Horn J, Mikolajczyk RT, et al. Estimations of worldwide prevalence of chronic hepatitis B virus infection: a systematic review of data published between 1965 and 2013. Lancet. 2015;386(10003):15461555.

3. Health Protection Agency. Health Protection Report. 2012.

4. European Association for the Study of the Liver. EASL 2017 Clinical Practice Guidelines on the management of hepatitis B virus infection. J Hepatol. 2017;67(2):370398.

5. Liang TJ, Block TM, McMahon BJ, et al. Present and future therapies of hepatitis $B$ : from discovery to cure. Hepatology. 2015;62(6):1893-1908.

6. Bertoletti A, Kennedy PT. The immune tolerant phase of chronic HBV infection: new perspectives on an old concept. Cell Mol Immunol. 2015;12(3):258-263.

7. Chu CJ, Hussain M, Lok AS. Quantitative serum HBV DNA levels during different stages of chronic hepatitis B infection. Hepatology. 2002;36(6):1408-1415.

8. Fong TL, Di Bisceglie AM, Gerber MA, et al. Persistence of hepatitis $B$ virus DNA in the liver after loss of $\mathrm{HBs} \mathrm{Ag}$ in chronic hepatitis B. Hepatology. 1993;18(6):1313-1318.

9. Loomba R, Liang TJ. Hepatitis B reactivation associated with immune suppressive and biological modifier therapies: current concepts, management strategies and future directions. Gastroenterology. 2017;152(6): 1297-1309.
10. Hoofnagle JH. Reactivation of hepatitis B. Hepatology. 2009; 49(5):156-165.

11. Lok AS, Liang RH, Chiu EK, et al. Reactivation of hepatitis $B$ virus replication in patients receiving cytotoxic therapy. Report of a prospective study. Gastroenterology. 1991;100(1):182-188.

12. Seto WK, Chan TS, Hwang YY, et al. Hepatitis $B$ reactivation in patients with previous hepatitis $B$ virus exposure undergoing rituximab-containing chemotherapy for ymphoma: a prospective study. J Clin Oncol. 2014;32(33):3736-3743.

13. Hammond SP, Borchelt AM, Ukomadu C, et al. Hepatitis B virus reactivation following allogeneic hematopoietic stem cell transplantation. Biol Blood Marrow Transplant. 2009;15(9):1049-1059.

14. Yeo W, Chan PK, Zhong S, et al. Frequency of hepatitis $B$ virus reactivation in cancer patients undergoing cytotoxic chemotherapy: a prospective study of 626 patients with identification of risk factors. J Med Virol. 2000;62(3):299-307.

15. Yuen MF, Wong DK, Fung J, et al. HBsAg seroclearance in chronic hepatitis B in Asian patients: replicative level and risk of hepatocellular carcinoma. Gastroenterology. 2008;135(4):1192-1199.

16. Lau GK, Leung YH, Fong DY, et al. High hepatitis $B$ virus (HBV) DNA viral load as the most important risk factor for HBV reactivation in patients positive for HBV surface antigen undergoing autologous hematopoietic cell transplantation. Blood. 2002;99(7) 2324-2330.

17. Perrillo RP. Acute flares in chronic hepatitis $B$ : the natural and unnatural history of an immunologically mediated liver disease. Gastroenterology. 2001;120(4):1009-1022.

18. Paul S, Dickstein A, Saxena A, et al. Role of surface antibody in hepatitis $B$ reactivation in patients with resolved infection and hematologic malignancy: a meta-analysis Hepatology. 2017;66(2):379-388.

19. De Monte A, Courjon J, Anty R, et al. Direct-acting antiviral treatment in adults infected with hepatitis $\mathrm{C}$ virus: reactivation of hepatitis B virus coinfection as a further challenge. J Clin Virol. 2016;78:27-30

20. Wang C, Ji D, Chen J, et al. Hepatitis due to reactivation of hepatitis $B$ virus in endemic areas among patients with hepatitis $C$ treated with direct-acting antiviral agents. Clin Gastroenterol Hepatol. 2017;15(1):132-136.

21. Calvaruso V, Ferraro D, Licata A, et al. HBV reactivation in patients with $\mathrm{HCV} / \mathrm{HBV}$ cirrhosis on treatment with direct acting antivirals. J Viral Hepat. 2018;25(1):72-79.

22. Nath A, Agarwal R, Malhotra P, et al. Prevalence of hepatitis $B$ virus infection in non-Hodgkin lymphoma: a systematic review and meta-analysis. Intern Med J. 2010;40(9):633-641.

23. Marcucci F, Mele A. Hepatitis viruses and non-Hodgkin lymphoma: epidemiology, mechanisms of tumorigenesis, and therapeutic opportunities. Blood. 2011;117(6) 1792-1798

24. Marcucci F, Spada E, Mele A, et al. The association of hepatitis $B$ virus infection with $B$ cell non-Hodgkin lymphoma - a review. Am J Blood Res. 2012;2(1):18-28.

25. Perrillo RP, Gish R, Falck-Ytter YT. American Gastroenterological Association Institute technical review on prevention and treatment of hepatitis B virus reactivation during immunosuppressive drug therapy. Gastroenterology. 2015;148(1):221-244.

26. Paul S, Saxena A, Terrin N, et al. Hepatitis B virus reactivation and prophylaxis during solid tumour chemotherapy: A systematic review and meta-analysis. Ann Intern Med. 2016;164(1):30-40. 
27. Lam KC, Lai CL, Trepo C, et al. Deleterious effect of prednisolone in HBsAg-positive chronic active hepatitis. N Engl J Med. 1981:304(7):380-386.

28. Tur-Kaspa R, Shaul Y, Moore DD, et al. The glucocorticoid receptor recognizes a specific nucleotide sequence in hepatitis B virus DNA causing increased activity of the HBV enhancer. Virology. 1988;167(2):630-633.

29. Cheng AL, Hsiung CA, Su IJ, et al. Steroidfree chemotherapy decreases risk of hepatitis $B$ virus (HBV) reactivation in HBV-carriers with lymphoma. Hepatology. 2003;37(6): 1320-1328.

30. Westhoff TH, Jochimsen F, Schmittel A, et al. Fatal hepatitis B virus reactivation by an escape mutant following rituximab therapy. Blood. 2003;102(5):1930.

31. Sarrecchia C, Cappelli A, Aiello P. HBV reactivation with fatal fulminating hepatitis during rituximab treatment in a subject negative for $\mathrm{HBsAg}$ and positive for $\mathrm{HBsAb}$ and HBcAb. J Infect Chemother. 2005;11(4):189191.

32. Law JK, Ho JK, Hoskins PJ, et al. Fatal reactivation of hepatitis $B$ post-chemotherapy for lymphoma in a hepatitis B surface antigennegative, hepatitis $\mathrm{B}$ core antibody-positive patient: potential implications for future prophylaxis recommendations. Leuk Lymphoma. 2005;46(7):1085-1089.

33. Yamagata M, Murohisa T, Tsuchida K, et al. Fulminant $B$ hepatitis in a surface antigen and hepatitis B DNA-negative patient with diffuse large B-cell lymphoma after $\mathrm{CHOP}$ chemotherapy plus rituximab. Leuk Lymphoma. 2007;48(2):431-433.

34. Dillon R, Hirschfield GM, Allison ME, et al. Fatal reactivation of hepatitis B after chemotherapy for lymphoma. BMJ. 2008;337:a423.

35. Kusumoto S, Arcaini L, Hong X, et al. Risk fo HBV reactivation in patients with B-cell lymphomas receiving obinutuzumab or rituximab immunochemotherapy. Blood. 2019:133(2):137-146.

36. Pei SN, Ma MC, Wang MC, et al. Analysis of hepatitis B surface antibody titers in B cell lymphoma patients after rituximab therapy. Ann Hematol. 2012;91(7):1007-1012.

37. Visco C, Finotto S. Hepatitis $C$ virus and diffuse large B-cell lymphoma: Pathogenesis behavior and treatment. World J Gastroenterol. 2014;20(32):11054-11061.

38. Iannitto E, Minardi V, Calvaruso G, et al. Hepatitis B virus reactivation and alemtuzumab therapy. Eur J Haematol. 2005:74(3):254-258

39. Moses SE, Lim ZY, Sudhanva M, et al. Lamivudine prophylaxis and treatment of hepatitis B virus-exposed recipients receiving reduced intensity conditioning hematopoietic stem cell transplants with alemtuzumab. J Med Virol. 2006;78(12):1560-1563

40. Ifuku $\mathrm{H}$, Kusumoto $\mathrm{S}$, Tanaka $Y$, et al. Fatal reactivation of hepatitis $B$ virus infection a patient with adult T-cell leukemia-lymphoma receiving the anti-CC chemokine receptor 4 antibody mogamulizumab. Hepatol Res. 2015;45(13):1363-1367.

41. Totani H, Kusumoto S, Ishida T, et al. Reactivation of hepatitis B virus (HBV) infection in adult T-cell leukemia-lymphoma patients with resolved HBV infection following systemic chemotherapy. Int J Hematol. 2015;101(4):398-404.

42. Yang H, Cao Z, Wang Z, et al. Hepatitis B virus reactivation induced by brentuximab vedotin in the treatment of Hodgkin lymphoma: a case report and literature review. Zhonghua Xue Ye Xue Za Zhi.
2014:35(10):949-950

43. Seto WK, Chan TS, Hwang YY, et al. Hepatitis B reactivation in occult viral carriers undergoing hematopoietic stem cell transplantation: A prospective study. Hepatology. 2017;65(5):1451-1461.

44. Lindemann M, Koldehoff M, Fiedler M, et al. Control of hepatitis B virus infection in hematopoietic stem cell recipients after receiving grafts from vaccinated donors. Bone Marrow Transplant. 2016;51(3):428431.

45. Hwang JP, Lok AS. Management of patients with hepatitis $B$ who require immunosuppressive therapy. Nat Rev Gastroenterol Hepatol. 2014:11(4):209-219.

46. Jun $\mathrm{CH}$, Kim BS, Oak CY, et al. HBV reactivation risk factors in patients with chronic $\mathrm{HBV}$ infection with low replicative state and resolved HBV infection undergoing hematopoietic stem cell transplantation in Korea. Hepatol Int. 2017;11(1):87-95.

47. Socie G, Ritz J. Current issues in chronic graft-versus-host disease. Blood. 2014;124 (3):374-384

48. Huang $\mathrm{H}$, Cai $\mathrm{Q}$, Lin $\mathrm{T}$, et al. Lamivudine for the prevention of hepatitis $\mathrm{B}$ virus reactivation after high-dose chemotherapy and autologous hematopoietic stem cell transplantation for patients with advanced or relapsed non-Hodgkin's lymphoma single institution experience. Expert Opin Pharmacother. 2009;10(15):2399-2406.

49. Varma A, Biritxinaga L, Saliba RM, et al Impact of hepatitis B core antibody seropositivity on the outcome of autologous hematopoietic stem cell transplantation for multiple myeloma. Biol Blood Marrow Transplant. 2017;23(4):581-587.

50. Harris AE, Styczynski J, Bodge M, et al Pretransplant vaccinations in allogeneic stem cell transplantation donors and recipients: an often-missed opportunity for immunoprotection? Bone Marrow Transplant. 2015;50 (7):899-903.

51. Lindemann M, Barsegian V, Runde V, et al Transfer of humoral and cellular hepatitis B immunity by allogeneic hematopoietic cell transplantation. Transplantation. 2003;75(6): 833-838.

52. Ikeda K, Shiga Y, Takahashi A, et al. Fatal hepatitis $\mathrm{B}$ reactivation in a chronic myeloid leukemia patient during imatinib mesylate treatment. Leuk Lymphoma. 2006;47(1) 155-157.

53. Lai GM, Yan SL, Chang CS, et al. Hepatitis B reactivation in chronic myeloid leukaemia patients receiving tyrosine kinase inhibitor. World J Gastroenterol. 2013;19(8):1318 1321

54. Lakhani S, Davidson L, Priebat DA, et al. Reactivation of chronic hepatitis $B$ infection related to imtinib mesylate therapy. Hepatol Int. 2008:2(4):498-499.

55. Kang BW, Lee SJ, Moon JH, et al. Chronic myeloid leukemia patient manifesting fatal hepatitis B virus reactivation during treatment with imatinib rescued by liver transplantation: case report and literature review. Int J Haematol. 2009:90(3):383-387.

56. De Jesus Ngoma P, Kabamba B, Dahlqvist G et al. Occult HBV reactivation induced by ibrutinib treatment: a case report. Acta Gastroenterol Belgica. 2015;78(4):424-426.

57. Li J, Huang B, Li Y, et al. Hepatitis B virus reactivation in patients with multiple myeloma receiving bortezomib-containin regiments followed by autologous stem cell transplant. Leuk Lymphoma. 2015;56(6): 1710-1717.

58. Shen $\mathrm{CH}$, Hwang CE, Chen $\mathrm{YY}$, et al. Hepatitis B virus reactivation associated with ruxolitinib. Ann Haematol. 2014;93 (6):1075-1076

59. Caocci G, Murgia F, Podda L, et al Reactivation of hepatitis B virus infection following ruxolitinib treatment in a patient with myelofibrosis. Leukemia. 2014;28(1) 225-227.

60. Michot JM, Bigenwald C, Champiat S, et al. Immune-related adverse events with immune checkpoint blockade: a comprehensive review. Eur J Cancer. 2016;54:139148.

61. Sanjeevaiah A, Kerr T, Beg MS. Approach and management of checkpoint inhibitorrelated immune hepatitis. J Gastrointest Oncol. 2018:9(1):220-224.

62. Koksal AS, Toka B, Eminler AT, et al. HBVrelated acute hepatitis due to immune checkpoint inhibitors in a patient with malignant melanoma. Ann Oncol. 2017;28 (12):3103-3104.

63. Pandey A, Ezemenari S, Liaukovich M, et al A rare case of Pembrolizumab-induced reactivation of hepatitis B. Case Rep Oncol Med. 2018;2018:5985131.

64. Bertoletti A, Le Bert N. Immunotherapy for chronic hepatitis B virus infection. Gut Liver. 2018;12(5):497-507.

65. Chaganti $S$, Illidge $T$, Barrington $S$, et al Guidelines for the management of diffuse large B-cell lymphoma. Br J Haematol. 2016;174(1):43-56.

66. Squadrito G, Spinella R, Raimondo G. The clinical significance of occult HBV infection. Ann Gastroenterol. 2014;27(1):15-19.

67. Huang YH, Hsiao LT, Hong YC, et al Randomised controlled trial of entecavir prophylaxis for rituximab-associated hepatitis $B$ virus reactivation in patients with lymphoma and resolved hepatitis B. J Clin Oncol. 2013;31(22):2765-2772.

68. Lau GK, Yiu HH, Fong DY, et al. Early is superior to deferred preemptive lamivudine therapy for hepatitis B patients undergoing chemotherapy. Gastroenterology. 2003;125 (6):1742-1749.

69. Hsu C, Hsiung CA, Su IJ, et al. A revisit of prophylactic lamivudine for chemotherapyassociated hepatitis B reactivation in nonHodgkin's lymphoma: a randomised trial Hepatology. 2008;47(3):844-853

70. Loomba R, Rowley A, Wesley R, et al Systematic review: the effect of preventive lamivudine on hepatitis B reactivation during chemotherapy. Ann Intern Med. 2008;148(7):519-528

71. Kohrt HE, Ouyang DL, Keefe EB. Systematic review: lamivudine prophylaxis for chemotherapy-induced reactivation of chronic hepatitis B virus infection. Aliment Pharmacol Ther. 2006;24(7):1003-1016.

72. Lok AS, Hussain M, Cursano C, et al Evolution of hepatitis B virus polymerase gene mutations in hepatitis $B$ e antigen-negative patients receiving lamivudine therapy. Hepatology. 2000;32(5):1145-1153.

73. Huang $\mathrm{H}$, Li X, Zhu J, et al. Entecavir vs lamivudine for prevention of hepatitis $\mathrm{B}$ virus reactivation among patients with untreated diffuse large B-cell lymphoma receiving $\mathrm{R}-\mathrm{CHOP}$ chemotherapy: a randomized control trial. JAMA. 2014;312(23): 2521-2530.

74. Hilgendorf I, Loebermann M, Borchert K, et al. Tenofovir for treatment of hepatitis $B$ virus reactivation in patients with chronic GVHD. Bone Marrow Transplant. 2011;46 (9):1274-1275

75. Woodward CLN, Hall AM, Williams IG, et al. Tenofovir-associated renal and bone toxicity. HIV Med. 2009;10(8):482-487.

76. Agarwal K, Brunetto M, Seto WK, et al. 96 
weeks treatment of tenofovir alafenamide vs. tenofovir disoproxil fumarate for hepatitis B virus infection. J Hepatol. 2018;68(4): 672-681.

77. Buti M, Gane R, Seto WK, et al. Tenofovir alafenamide versus tenofovir disoproxil fumarate for the treatment of patients with HBeAg-negative chronic hepatitis $B$ virus infection: a randomised, double-blind, phase 3 , non-inferiority trial. Lancet Gastroenterol Hepatol. 2016;1(3):196-206.

78. Chan HL, Fung S, Seto WK, et al. Tenofovir alafenamide versus tenofovir disoproxil fumarate for the treatment for $\mathrm{HBeAg}$-positive chronic hepatitis $B$ virus infection: a randomised, double-blind, phase 3, non-inferiority trial. Lancet Gastroenterol Hepatol. 2016;1(3):185-195.

79. Myers RP, Swain MG, Urbanski SJ, et al. Reactivation of hepatitis $B$ e antigen-negative chronic hepatitis $B$ in a bone marrow transplant recipient following lamivudine withdrawal. Can J Gastroenterol. 2001;15 (9):599-603.

80. Takahata M, Hashino S, Onozawa M, et al Hepatitis $B$ virus (HBV) reverse seroconver- sion (RS) can be prevented even in nonresponders to hepatitis $\mathrm{B}$ vaccine after allogeneic stem cell transplantation: long-term analysis of intervention in $\mathrm{RS}$ with vaccine for patients with previous HBV infection Transpl Infect Dis. 2014; 16(5):797-801.

81. Onozawa M, Hashino S, Darmanin S, et al. $\mathrm{HB}$ vaccination in the prevention of vira reactivation in allogeneic hematopoietic stem cell transplantation recipient with previous $\mathrm{HBV}$ infection. Biol Blood Marrow Transplant. 2008;14(11):1226-1230. 